\title{
BMJ Open Demographics and health profile on precursors of non-communicable diseases in adults testing for HIV in Soweto, South Africa: a cross- sectional study
}

\author{
Kathryn L Hopkins, ${ }^{1,2}$ Khuthadzo Hlongwane, ${ }^{1}$ Kennedy Otwombe, ${ }^{1}$ \\ Janan Dietrich, ${ }^{1,3}$ Mireille Cheyip, ${ }^{4}$ Nompumelelo Khanyile, ${ }^{4}$ Tanya Doherty, ${ }^{2,3}$ \\ Glenda E Gray ${ }^{1,5}$
}

To cite: Hopkins KL, Hlongwane K, Otwombe K, et al. Demographics and health profile on precursors of non-communicable diseases in adults testing for HIV in Soweto, South Africa: a crosssectional study. BMJ Open 2019;9:e030701. doi:10.1136/ bmjopen-2019-030701

- Prepublication history for this paper is available online. To view these files, please visit the journal online (http://dx.doi. org/10.1136/bmjopen-2019030701).

Received 01 April 2019 Revised 14 October 2019 Accepted 06 November 2019

Check for updates

(C) Author(s) (or their employer(s)) 2019. Re-use permitted under CC BY-NC. No commercial re-use. See rights and permissions. Published by BMJ.

For numbered affiliations see end of article.

Correspondence to

Kathryn L Hopkins;

HopkinsK@phru.co.za

\section{ABSTRACT}

Objectives This cross-sectional study investigated the burden of HIV-non-communicable disease (NCD) precursor comorbidity by age and sex. Policies stress integrated HIV-NCD screenings; however, NCD screening is poorly implemented in South African HIV testing services (HTS). Setting Walk-in HTS Centre in Soweto, South Africa. Participants 325 voluntary adults, aged $18+$ years, who provided written or verbal informed consent (with impartial witness) for screening procedures were enrolled. Primary and secondary outcomes Data on sociodemographics, tuberculosis and sexually transmitted infection symptoms, blood pressure (BP) $(\geq 140 / 90=$ elevated) and body mass index $(<18.5$ underweight; 18.5-25.0 normal; >25 overweight/obese) were stratified by age-group, sex and HIV status. Results 0 the 325 participants, the largest proportions were female $(51.1 \%$; $n=166 / 325)$, single $(71.5 \%$; $\mathrm{n}=231 / 323)$ and $25-34$ years $(33.8 \% ; \mathrm{n}=110 / 325)$. Overall, 20.9\% ( $n=68 / 325)$ were HIV infected, $27.5 \%$ ( $n=89 / 324)$ had high BP and 33.5\% ( $n=109 / 325)$ were overweight/obese. Among HIV-infected participants, $20.6 \%(14 / 68)$ had high BP and 30.9\% (21/68) were overweight/obese, as compared with $29.3 \%$ (75/256) and $12.1 \%(31 / 256)$ of the HIV-uninfected participants, respectively. Females were more likely HIV-infected compared with males (26.5\% (44/166) vs $15.1 \%$ (24/159); $p=0.012)$. In both HIV-infected and uninfected groups, high BP was most prevalent in those aged 35-44 years $(25 \%(6 / 24)$ vs $36 \%(25 / 70) ; p=0.3353)$ and $>44$ years $(29 \%(4 / 14)$ vs $48 \%(26 / 54) ; p=0.1886)$. Males had higher BP than females $(32.9 \%(52 / 158)$ vs $22.3 \%$ (37/166); $p=0.0323)$; more females were overweight/ obese relative to males $(45.8 \%$ (76/166) vs $20.8 \%$ (33/159); $p<0.0001)$. Females were more likely to be HIV infected and overweight/obese.

Conclusion Among HTS clients, NCD precursors rates and co-morbidities were high. Elevated BP occurred more in older participants. Targeted integrated interventions for HIV-infected females and HIV-infected people aged 18-24 and 35-44 years could improve HIV public health outcomes. Additional studies on whether integrated HTS

\section{Strengths and limitations of this study}

- This study established the previously unknown level of comorbidity of non-communicable disease (NCD) precursors among adults presenting to a standard of care HIV testing services (HTS) centre in Soweto, South Africa.

- This study investigates NCD precursor and HIV comorbidity by sex and age group (18-24 years, 2534 years, $35-44$ years and $\geq 45$ years) to determine demographics of higher risk.

- This study has a convenience sample of participants self-selecting to attend a single HTS clinic in Soweto. There is potential for bias as these participants were not randomly sampled from multiple facilities.

- As standard of care HTS includes syndromic screening for sexually transmitted infections (STIs) and tuberculosis (TB), this study was not able to confirm suspected STIs and TB with diagnostic testing in clinic.

will improve the uptake of NCD treatment and improve health outcomes are required.

\section{INTRODUCTION}

The epicentre of the HIV epidemic is South Africa which is estimated to have 7.9 million people living with HIV (PLHIV) and has a high HIV prevalence among the general population aged $15-49$ years $(20.6 \%) .{ }^{1}$ South Africa's colliding epidemics of HIV/AIDS, and other communicable and chronic noncommunicable diseases (NCDs), specifically HIV-NCD comorbidities, may complicate HIV treatment and impact survival. ${ }^{2} 3$ To combat this, the South African National HIV Testing Services (HTS) Policy and Guidelines $2015^{4}$ stresses the importance of integrating screening efforts for HIV, tuberculosis (TB), 
sexually transmitted infections (STIs) and NCDs. ${ }^{4}$ Globally, South Africa has the highest estimated TB incidence among PLHIV with nearly $200000 \mathrm{~TB} / \mathrm{HIV}$ cases in $2017 .{ }^{56}$ In South Africa, $3.4 \%$ of new TB cases and $7.1 \%$ of previously treated TB cases are multidrug resistant/ rifampicin resistant. ${ }^{6}$ The STI prevalence in South Africa is high, ${ }^{7}$ though there is no baseline epidemiological data that exists. ${ }^{8}$ Additionally, the prevalence of chronic NCDs is predicted to cause almost three-quarters as many deaths as communicable, maternal, perinatal and nutritional disease combined by 2020, exceeding them as the most common causes of death by 2030 in Africa. ${ }^{9}$

While the KwaZulu-Natal Province has the highest HIV prevalence (27.0\%) out of South Africa's nine provinces, ${ }^{1}$ the Gauteng Province has the highest number of new HIV infections. ${ }^{10}$ Another cause for concern is the rise of precursors of NCDs, such as obesity and high blood pressure (BP) within this province. The South African Demographics and Health Survey (SADHS) in 2016 reported about one-in-five Gauteng residents are severely obese (body mass index (BMI) $\geq 35$ ), and the province's prevalence of hypertension in women and men aged 15 years or older to be $42.3 \%$ and $39.5 \%$, respectively. The prevalence of hypertension is slightly higher for the black/African ethnic group, and increased even more for women and men in urban areas of residence $(46.5 \%$ and $45.4 \%)^{11}$

Soweto, the largest group of urban African townships in South Africa, falls within the City of Johannesburg Metropolitan Municipality (JHB) district, Gauteng Province. ${ }^{12}$ By 2003, the Greater Soweto area consisted of 87 townships grouped together into zones. ${ }^{7}$ Measuring $200 \mathrm{~km}^{2}$, it holds a population of about 1.3 million people which has increased by $48.1 \%$ in the last 10 years. ${ }^{68}$ With South African townships known to have a higher HIV prevalence and the SADHS reporting urban populations have a higher prevalence of NCD precursors than the overall national prevalence, ${ }^{11}{ }^{13}$ the community of Soweto could be one of the most vulnerable populations to HIV-NCD comorbidities. ${ }^{12}$ Collecting data on the health status of the general population of Soweto could prove useful in understanding the true burden of comorbid disease and provide insight to prevention and treatment programmes.

Black Africans comprise $98.1 \%$ of the population in Soweto. ${ }^{14}$ While there has been a large collection of data depicting the health profile of Gauteng province and the $\mathrm{JHB}$ district, there is a paucity of literature on the burden of disease affecting the general population of Soweto. Existing data are largely from studies targeting key populations, and/or age or sex groups. For example, there is no systematically collected and reported baseline STI prevalence data for Soweto, however studies have clearly explained the STI health profile of men who have sex with men and for adolescents residing in Soweto. ${ }^{1516}$ The Heart of Soweto Study established a prospective registry of men and women from Soweto presenting with heart disease to the Chris Hani Baragwanath Academic (Bara) Hospital. ${ }^{17}$ Preliminary results published in 2006 from information collected on $12000+$ men and women identified cardiovascular disease in $35 \%$ of the individuals, with almost a quarter affected aged below 40 years. Two of the five most common diagnoses overall were hypertension $(54 \%)$ and diabetes $(10 \%) .{ }^{17}$

The South African National HTS: Policy and Guidelines ${ }^{4}$ call for integrated screenings was adopted from the WHO Consolidated Guidelines on HIV Counselling and Testing (HCT) ${ }^{18}$ a collation of evidence-based best practices for effective delivery of HTS and subsequent linkage to HIV prevention, care and treatment services. The global guidance, as well as the national policy, also focus on supporting the Joint United Nations Programme on HIV/AIDS 90-90-90 global HIV targets. ${ }^{19}$ The aim of 90-90-90 is to diagnose $90 \%$ of all HIV-infected persons, provide antiretroviral therapy (ART) for $90 \%$ of those diagnosed and achieve viral suppression for $90 \%$ of those treated by $2020 .^{19}$

The aim of this paper was to establish the level of comorbidity of NCD precursors among adults presenting to a standard of care HTS in Soweto, South Africa. Here we present baseline demographic and health profile data. National and global policies stress integrated screening to address NCD precursors (eg, BP and BMI). However, screening is poorly implemented in many South African HTS, and programmes need data for health planning.

\section{METHODS}

\section{Study design and setting}

This was a cross-sectional study which evaluated a health screening programme within the Zazi' HTS clinic at the Perinatal HIV Research Unit (PHRU), a leading research centre situated at the Bara Hospital in Soweto.

The PHRU Zazi HCT Clinic, which loosely translates from Zulu to English as 'Know Yourself', has provided on-site HIV testing and counselling for adults in Soweto since 2001. It also facilitates CD4 count testing for clients not yet initiated on treatment. Zazi initially conducted CD4 count screening as $>350$ cells $/ \mathrm{mm}^{3}$ was formerly required to start treatment. Now that a CD4 count threshold is no longer required to initiate treatment, Zazi still offers the test as an indicator of health for HIV-infected clients not yet on treatment. Zazi is currently the only service provider of walk-in, free, accessible HTS service supplied to Bara Hospital, the largest hospital in the southern hemisphere. HIV treatment is not provided on-site, but clients are given referral letters to local clinics.

To align itself with the global and national policies, the Zazi clinic expanded its health service provision in 2018, and began offering height and weight measurements, BP readings and symptom screenings for STIs and TB within its HTS. If required, clients were given referral letters for additional testing and treatment at their local government clinics; treatment was not provided on-site for any illness. In this manner, the Zazi clinic reflected the South African National Department of Health's (NDoH) newly proposed HTS standard of care. 


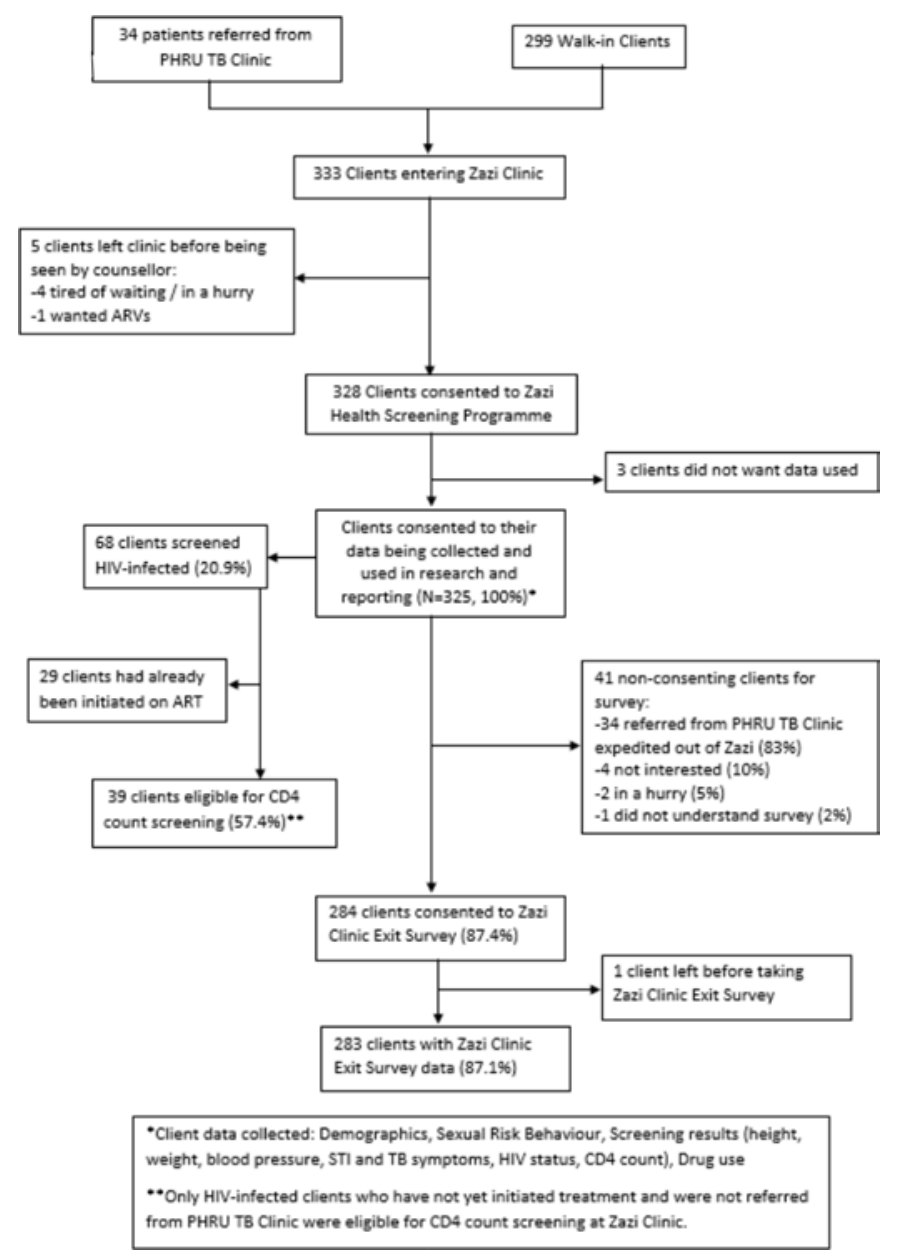

Figure 1 Participant flow chart for the Zazi clinic. PHRU, Perinatal HIV Research Unit; STI, sexually transmitted disease; TB, tuberculosis.

\section{Sampling and sample size}

The study sample was comprised of all eligible walk-in PHRU Zazi HTS clients, who consented for both the health screening programme and for their data to be captured and used in research, between 19 February 2018 and 14 June 2018. Any client who allowed the use of his/her health screening results and data via study consent were included in the aggregate data capture. If consent was not given, the client was still able to undergo health screening without data capture. All clients who consented to the programme and to data capture were then asked if they would like to partake in a clinic exit survey prior to leaving the clinic and consent was obtained. Figure 1 depicts the participant flow chart in Zazi.

\section{Inclusion and exclusion criteria}

Eligibility criteria for participation in the integrated screenings were the following: at least 18 years of age; able to communicate in either English, IsiZulu and/or Sotho; and able and willing to provide written or verbal informed consent (with impartial witness) for health screening procedures. If a client presented to the clinic and there was immediate cause for concern, they were excluded from the programme and redirected to the Bara casualty ward.

\section{Data collection and management}

Client demographic and clinic exit survey data were either self-collected by literate clients in the reception area, or collected with help of the clinic receptionist or lay counsellors for clients unable to read or write. Clinical data were collected by the study lay counsellors and enrolled nurse while in private rooms through consultation with the client. Demographic, behavioural and clinical data were collected through screenings and questionnaires and recorded onto paper forms comprising PHRU Zazi HTS client file. Clinical data collected included health profile and screening results (see Study measures: Health profile and screening results section below) and client interest in pre-exposure prophylaxis (PrEP). Source documents were the client file and CD4 count pathology reports as accessed and printed by the enrolled nurse from the electronic National Health Laboratory Services InterSystems' TrakCare Laboratory Information System.

The Programme Manager and statistician led data cleaning checks prior to clinical staff entering data into the electronic database (REDCap), performing a 100\% crosscheck of all captured data against the client files for verification purposes.

\section{Study measures}

\section{Demographic and substance use information}

Data were collected on sex, age, race, nationality, ethnic group, marital status, highest level of education, employment, details regarding home residence-type of housing, source of water and fuel for cooking and lighting, type of toilet facility, as well as possession of household and ownership items.

A wealth quintile was developed using the socioeconomic measures and determined using Principal Component Analysis (PCA). ${ }^{20-22}$ The socioeconomic measures included the following variables: type of house, source of water, type of toilet facility; type of fuel used for cooking; type of fuel used for lighting; possession of household items and other ownership items. Prior to calculating the wealth quintile, variables with more than two levels were recoded into binary ( 0 or 1$)$ for each level of response. Frequencies were run on all the binary variables and only those with responses between $5 \%$ and $95 \%$ were retained. The retained variables were evaluated by the PCA method using the varimax rotation to identify those contributing largely to the wealth construct. Variables meeting a prespecified cut-off and loading in at least two factors were excluded. The remaining variables were retained and scored to create the socioeconomic index. Five wealth quintiles were estimated on the scored measure using 20 percentile intervals.

Additional information was collected on substance use including how often clients drank alcohol in the last year and number of drinks per occasion, usage of illicit drugs and type of illicit drugs, current cigarette smoking status and number of cigarettes smoked per day. Questions 
surrounding alcohol, tobacco and drug use were taken from the validated 2003 SADHS. ${ }^{23}$

Health profile and screening results

Client health profile and screening results include BMI, $\mathrm{BP}$ readings, STI and TB symptoms, HIV results and CD4 count.

$B M I$ was calculated by dividing client weight (in $\mathrm{kg}$ ) by the square of height (in $\mathrm{m}^{2}$ ) and classified as underweight, normal, overweight and obese using the WHO classification. ${ }^{24}$ Overweight and obese categories were merged resulting in three categories.

$B P$ was classified as high, normal or low using systolic and diastolic BP. High BP was defined as $>140 / 90 \mathrm{~mm} \mathrm{Hg}$, normal BP was considered $\leq 140 / 90$ and $\geq 90 / 60 \mathrm{~mm} \mathrm{Hg}$, and low BP was classified as $<90 / 60 \mathrm{~mm} \mathrm{Hg}$. If the first measurement was high or low then a second BP reading was conducted, and an average $\mathrm{BP}$ was used for the classification. BP cut-offs used were from the South African Hypertension Practice Guidelines, as per standard of care. $^{25}$

STI symptoms were defined as having at least one of the following symptoms: (1) abnormal, bad-smelling or itchy discharge from the vagina/penis/anus; (2) any blood coming from the vagina/penis/anus; (3) current sores on/in vagina/penis/anus; (4) burning sensation while passing urine and/or (5) any lower abdominal pain (if female).

TB symptoms were defined as having one or more of the following symptoms: (1) cough for more than 2 weeks, (2) blood in the sputum, (3) persistent fever and/or night sweats for more than 2 weeks, (4) weight loss of $\geq 1.5 \mathrm{~kg}$ in the last month and/or (5) lived with someone who has/had TB in the last month. ${ }^{26} \mathrm{~TB}$ symptoms were assessed for clients who were not already diagnosed with $\mathrm{TB}$ on entering the clinic.

The STI and TB symptom screening utilised standardised questions provided by the NDoH.

\section{Data analysis}

Descriptive statistics (eg,; medians and IQRs) were determined for continuous variables (eg, age, BMI and CD4 count). Frequencies and their percentages were determined for categorical variables and stratified by age group (18-24, 25-34, 35-44 and $\geq 45$ years), sex and HIV status where appropriate.

To test statistical significance for categorical measures stratified by sex, Fisher's exact test or $\chi^{2}$ analysis as appropriate was used. Continuous variables were compared by sex using the Kruskal-Wallis test. The distribution of precursors of NCDs (BMI and BP) were presented graphically by age-group and sex.

All statistical analysis was conducted in SAS Enterprise Guide V.7.1 (SAS Institute) using SAS/STAT procedures PROC FREQ, PROC NPAR1WAY and PROC FACTOR.

\section{Patient and public involvement}

This research was done without patient involvement. Patients were not invited to comment on the study design and were not consulted to develop patient relevant outcomes or interpret the results. We have invited our research community advisory board to help us disseminate our findings.

\section{Ethical considerations}

This study was reviewed in accordance with the Centers for Disease Control and Prevention human research protection procedures and was determined to be a research, but investigators did not interact with human subjects or had access to identifiable data or specimens for research purposes.

\section{RESULTS}

Demographic, substance use and health profile data were collected on 325 eligible walk-in Zazi clients.

\section{Demographics and substance use}

Males were significantly older than females (median (IQR) age $37.5(31.0-45.0)$ years vs 33.0 (26.0-41.0) years, respectively; $\mathrm{p}=0.001$ ) (table 1 ). The largest proportion of clients were female $(51.1 \%,(n=166 / 325))$, predominantly black Africans $(98.5 \% \quad(n=320 / 325))$, South African $(95.0 \% \quad(\mathrm{n}=305 / 321))$, Zulu-speaking $(41.7 \%(\mathrm{n}=135 / 324))$ and single $(71.5 \%(\mathrm{n}=231 / 323))$. About one-third had completed high school $(31.5 \%$ $(n=102 / 324))$, and the majority had initially come to Zazi for HIV testing $(96.3 \%(\mathrm{n}=313 / 325))$. Most clients belonged to the lower wealth quintiles: first quintile $(24.0 \%(78 / 325))$, second quintile $(26.8 \% \quad(\mathrm{n}=87 / 325))$ and third quintile $(24.9 \%(\mathrm{n}=81 / 325))$. Clients aged 25-34 and 35-44 years mostly fell within the first quintile $(28.2 \% \quad(n=31 / 110)$ and $28 \% \quad(n=26 / 94)$, respectively), whereas the younger age group (18-24 years) mostly reflected the second quintile $(40 \%(n=21 / 52))$. The oldest clients ( $\geq 45$ years) did not contribute towards the highest wealth quintile. Of clients with substance use data available, $11.0 \% \quad(n=32 / 290), 7.4 \% \quad(n=24 / 325)$ and 26.9\% ( $\mathrm{n}=78 / 290)$ reported drinking alcohol, using drugs weekly and ever smoked cigarettes, respectively. People aged 18-24years reported drinking alcohol on a monthly basis $(49 \%(\mathrm{n}=22 / 45))$ and drank $>4$ standardsize drinks per sitting $(75 \%(\mathrm{n}=24 / 32))$. Clients aged 25-34 years reported drinking weekly $(14 \% \quad(n=14 / 98))$ and monthly (38\% ( $\mathrm{n}=37 / 98)$, and among those who do drink, the majority drank $>4$ standard-size drinks per sitting $(72 \%(n=49 / 68))$. The majority of clients who reported having ever smoked cigarettes, still smoke $(99 \%$ $(\mathrm{n}=77 / 78))$ about 10 cigarettes per day $(43 \%(33 / 77))$. Of these, the highest proportion were aged $25-34(53 \%$ $(\mathrm{n}=16 / 30))$ and $35-44$ years $(52 \%(\mathrm{n}=11 / 21))($ table 1$)$.

\section{Communicable disease screening results}

Overall, 3.5\% ( $\mathrm{n}=11 / 318)$ had STI symptoms, $1.4 \%$ $(n=4 / 289)$ had TB symptoms and 20.9\% $(n=68 / 325)$ were HIV infected. There were 34 laboratory-confirmed TB clients who entered Zazi, and of those, 19 (56\%) were 
Table 1 Demographic characteristics and substance use by age group

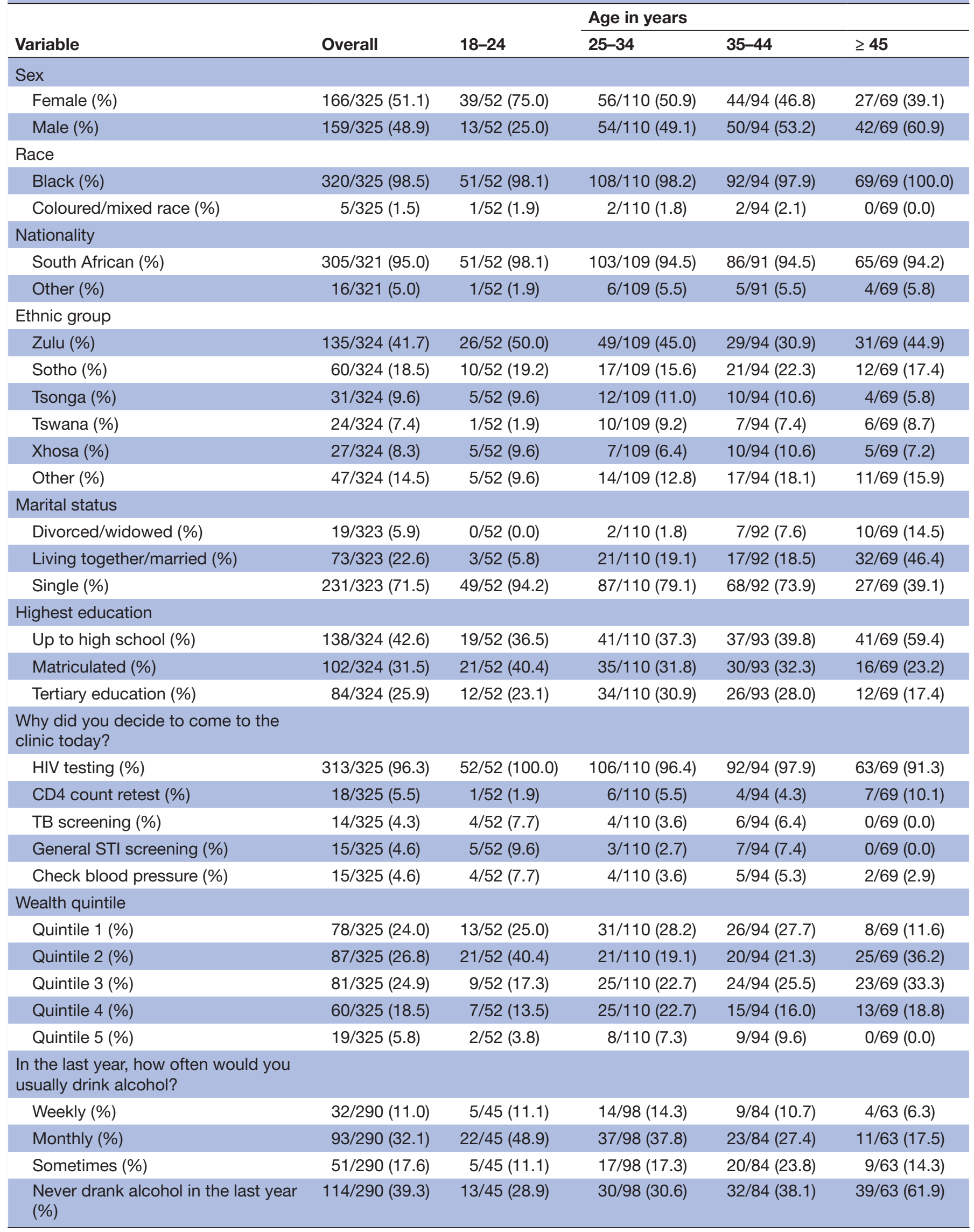


Table 1 Continued

\begin{tabular}{|c|c|c|c|c|c|}
\hline \multirow[b]{2}{*}{ Variable } & \multirow[b]{2}{*}{ Overall } & \multirow[b]{2}{*}{$18-24$} & \multicolumn{3}{|l|}{ Age in years } \\
\hline & & & $25-34$ & $35-44$ & $\geq 45$ \\
\hline \multicolumn{6}{|c|}{$\begin{array}{l}\text { About how many standard-size drinks } \\
\text { do you usually have in } 1 \text { day? }\end{array}$} \\
\hline $1-2(\%)$ & 25/175 (14.3) & 5/32 (15.6) & 7/68 (10.3) & 8/52 (15.4) & $5 / 23(21.7)$ \\
\hline 3-4 (\%) & $34 / 175(19.4)$ & $3 / 32(9.4)$ & 12/68 (17.6) & $12 / 52(23.1)$ & $7 / 23(30.4)$ \\
\hline$>4(\%)$ & $116 / 175(66.3)$ & 24/32 (75.0) & 49/68 (72.1) & $32 / 52(61.5)$ & $11 / 23(47.8)$ \\
\hline \multicolumn{6}{|l|}{ Do you use drugs? } \\
\hline Yes often (weekly) (\%) & 24/325 (7.4) & $3 / 52(5.8)$ & $15 / 110(13.6)$ & $2 / 94(2.1)$ & $4 / 69(5.8)$ \\
\hline Sometimes (\%) & 8/325 (2.5) & 2/52 (3.8) & $3 / 110(2.7)$ & 3/94 (3.2) & $0 / 69$ \\
\hline No (\%) & 293/325 (90.2) & 47/52 (90.4) & $92 / 110(83.6)$ & 89/94 (94.7) & 65/69 (94.2) \\
\hline \multicolumn{6}{|c|}{ Have you ever smoked cigarettes? } \\
\hline No (\%) & $212 / 290(73.1)$ & $29 / 45(64.4)$ & 68/98 (69.4) & 63/84 (75.0) & 52/63 (82.5) \\
\hline Yes (\%) & 78/290 (26.9) & $16 / 45(35.6)$ & 30/98 (30.6) & $21 / 84(25.0)$ & 11/63 (17.5) \\
\hline \multicolumn{6}{|c|}{ Do you still smoke cigarettes now? } \\
\hline No (\%) & $1 / 78(1.3)$ & $1 / 16(6.3)$ & 0/30 (0.0) & $0 / 21(0.0)$ & 0/11 (0.0) \\
\hline Yes (\%) & 77/78 (98.7) & 15/16 (93.8) & $30 / 30(100.0)$ & $21 / 21$ (100.0) & $11 / 11(100.0)$ \\
\hline \multicolumn{6}{|c|}{$\begin{array}{l}\text { About how many cigarettes do you or } \\
\text { did you usually smoke in } 1 \text { day? }\end{array}$} \\
\hline $1-2(\%)$ & 12/77 (15.6) & 2/15 (13.3) & $2 / 30(6.7)$ & 4/21 (19.0) & 4/11 (36.4) \\
\hline$<5(\%)$ & 27/77 (35.1) & 6/15 (40.0) & $12 / 30(40.0)$ & 4/21 (19.0) & 5/11 (45.5) \\
\hline $10(\%)$ & $33 / 77$ (42.9) & 5/15 (33.3) & 16/30 (53.3) & $11 / 21$ (52.4) & $1 / 11$ (9.1) \\
\hline 20 (\%) & 5/77 (6.5) & 2/15 (13.3) & $0 / 30(0.0)$ & 2/21 (9.5) & 1/11 (9.1) \\
\hline
\end{tabular}

The total frequencies for each variable do not necessarily equal the total sample size due to missing responses.

STI, sexually transmitted disease; TB, tuberculosis.

among the HIV infected. STI symptoms were highest in the group of people aged 18-24years $(10 \%(n=5 / 51))$. HIV infections were most prevalent in the group of aged $35-44$ years $(26 \%(n=24 / 94))$ followed by those $\geq 45$ years $(20 \%(\mathrm{n}=14 / 69))$ and $25-34$ years $(20.0 \%(\mathrm{n}=22 / 110))$. Of the 68 HIV-infected clients, 39 had their CD4 count measured (median CD4: 327 cells/mm ${ }^{3}$, IQR: 157-569). The remaining 29 HIV-infected clients were already in care, monitored regularly. A higher proportion of clients aged $\geq 45$ years were overweight/obese $(46 \% \quad(n=32 / 69))$ (table 2).

In comparing screening results by age groups, clients in age groups $35-44$ and $\geq 45$ years were more likely to be overweight/obese compared with the group aged 25-34years $\quad(37.2 \% \quad(\mathrm{n}=35 / 94) \quad$ vs $22.7 \% \quad(\mathrm{n}=25 / 110)$; $\mathrm{p}=0.0234)$ and $(46.4 \%(\mathrm{n}=32 / 69)$ vs $22.7 \%(\mathrm{n}=25 / 110)$; $\mathrm{p}=0.0009)$. The older age groups $(25-34,35-44$ and $\geq 44$ years) had significantly high proportions of high BP $(22.7 \%(\mathrm{n}=25 / 110)$ vs $5.8 \%(\mathrm{n}=3 / 52 ; \mathrm{p}=0.0077)),(33.0$ $(\mathrm{n}=31 / 94) \quad$ vs $5.8 \% \quad(\mathrm{n}=3 / 52 ; \mathrm{p}=0.0002)$ and $(44.1 \%$ $(\mathrm{n}=30 / 68)$ vs $5.8 \%(\mathrm{n}=3 / 52 ; \mathrm{p}<0.0001)$ relative to the younger age group (18-24 years). In addition, clients who were $\geq 45$ years were more likely to be obese compared with the group aged $25-34$ years $(44.1 \%(\mathrm{n}=30 / 68)$ vs $22.7 \%(\mathrm{n}=25 / 110) ; \mathrm{p}=0.0027)$.
Females obtained a significantly higher rate of HIV diagnosis than males $(26.5 \% \quad(n=44 / 166)$ vs $15.1 \%$ $(\mathrm{n}=24 / 159) ; \mathrm{p}=0.012)$ (table 2$)$. The proportion of males and females reporting no interest in learning about PrEP (95.6\% ( $\mathrm{n}=129 / 135)$ vs $91.8 \%(\mathrm{n}=112 / 122) ; \mathrm{p}=0.21)$ was similar between sex. Females were significantly more likely to be overweight/obese than males $(45.8 \%(n=76 / 166)$ vs $20.8 \%(\mathrm{n}=33 / 159) ; \mathrm{p}<0.001)$. A significantly higher number of males were diagnosed with high BP compared with females $(32.9 \%(n=52 / 158)$ vs $22.3 \%(n=37 / 166)$; $\mathrm{p}=0.032)$. Overall, $33.5 \%(\mathrm{n}=109 / 325)$ were overweight/ obese, $27.5 \%(n=89 / 324)$ and $1.5 \%(n=5 / 324)$ had high and low BP, respectively (table 2 ).

\section{NCD screening results, stratified by HIV status}

Both figure 2 and table 3 present the distribution of BP and BMI, stratified by age-group and sex for HIV-infected and HIV-uninfected clients. All HIV-infected clients aged $18-24$ years $(n=8)$ had normal BP readings, regardless of BMI (figure 2A, table 3). High BP readings increased with age with the highest readings being among the oldest age group ( $\geq 45$ years, $28.6 \%$ ). Though not significant, HIV-infected females had higher BP readings relative to HIV-infected males (25.0\% vs $12.5 \%$; $\mathrm{p}=0.22)$ (figure 2B, table 3). For HIV-uninfected clients, a similar BP trend 


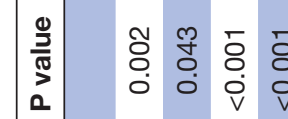

ํํㅎㅎํํํํำ

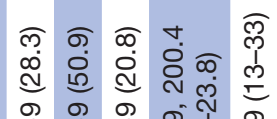

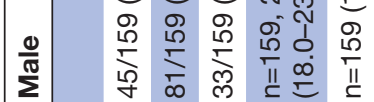

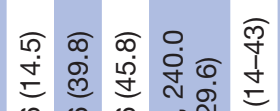

œ

สุ

ले

点

ธิ

ลู่ จุ

$\notin$ 눙

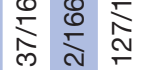

ळ

宅 峁 过

8 8 व 8 गे

部

ธุ

过 ๙

i

১্्ల @

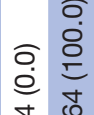

ปै

วิธตฺุ

过包 令主

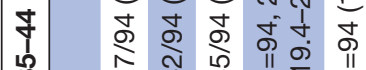

웅 을

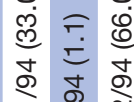

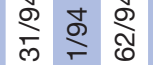

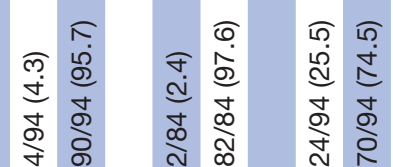

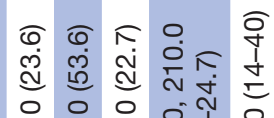

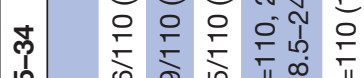

ผ

$\pi$ ก

กู่

욷 둥우

స્ฝ

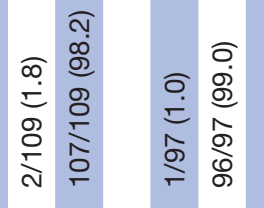

ㅇํㅇ

त्रे क्ठ

음으

నิ

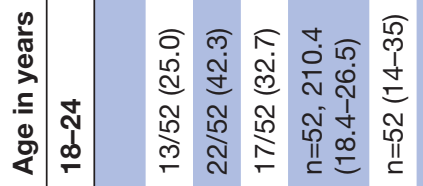

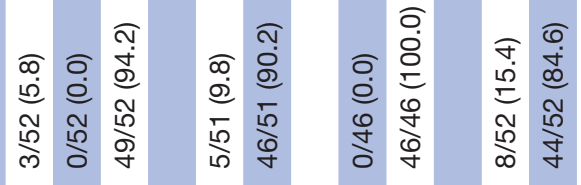

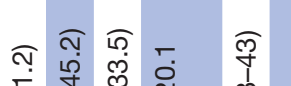

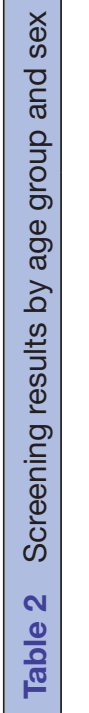
啇 造

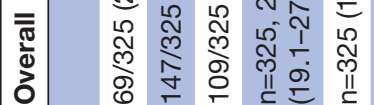

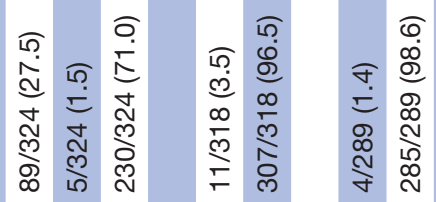

बृ.

న్లి

$\underset{\substack{m \\ 0}}{\stackrel{N}{N}}$

중

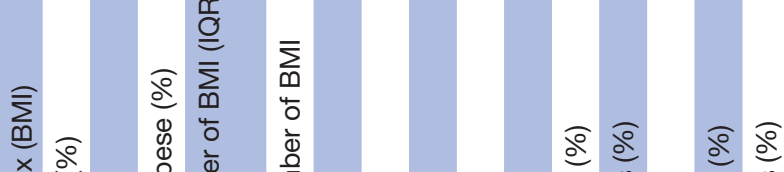

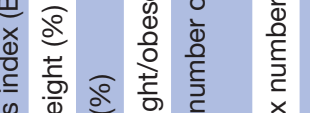

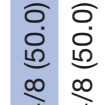

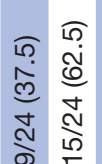

लू

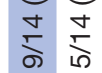

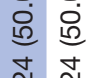

กิ

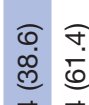

竝

ํㅜㅇ

寻

듬

ㅁำ

움

డ)

홍.

$\stackrel{\$}{1}$

은

ట్ర

욱

$\vec{v}$

ర్ల

敢

옹

ญ

흥

잉

혹

쿵

옥

赵

羿

을

옥

을.

กั

N

응 क융용

응

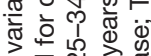




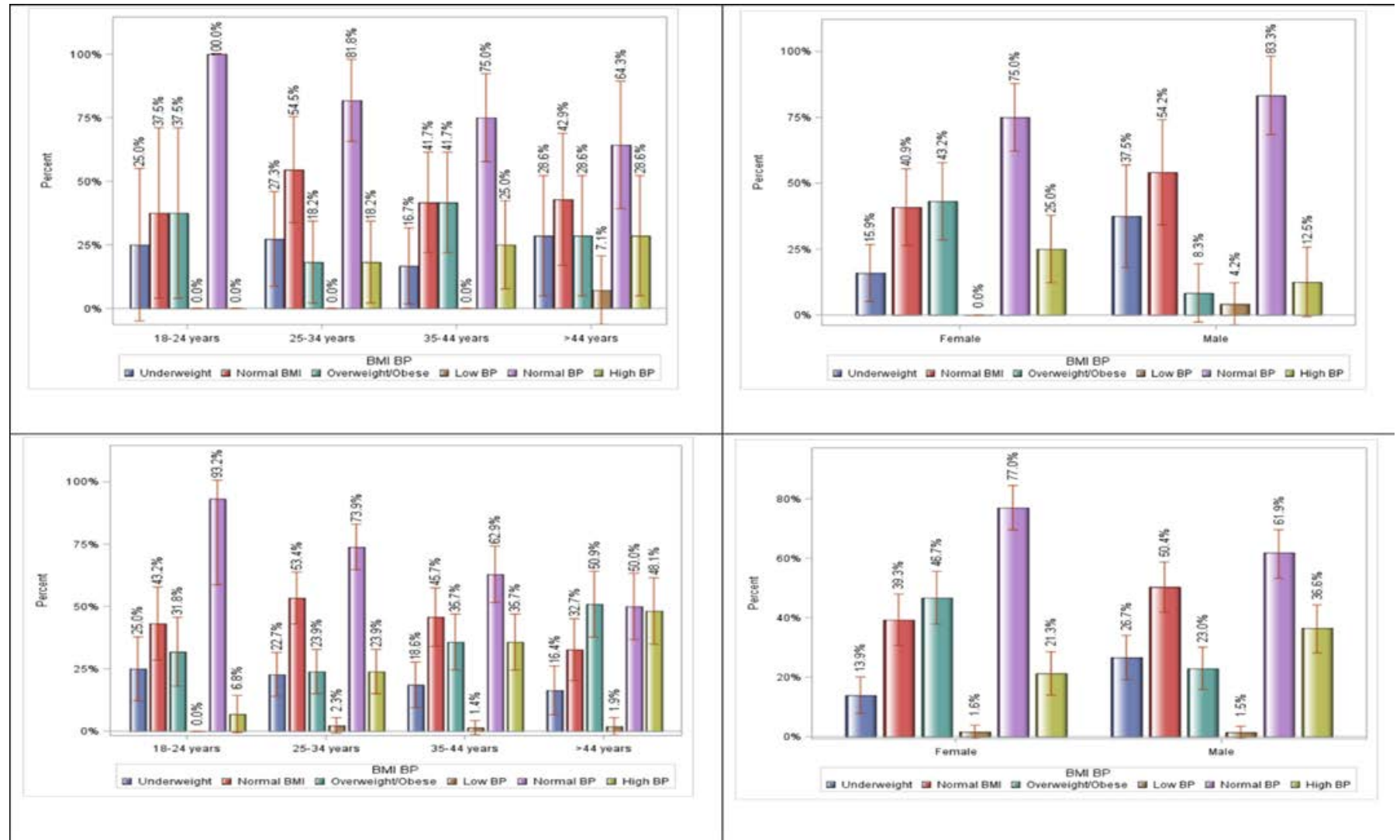

Figure 2 Distribution of BMI and BP by HIV status: (A) BMI and BP for HIV-infected people by age group (B) BMI and BP for HIV-infected people by sex. (C) BMI and BP for HIV-uninfected people by age group. (D) BMI and BP for HIV-uninfected people by age group. BMI, body mass index; BP, blood pressure.

was seen by age (figure 2C, table 3 ), while the opposite was seen by sex (figure 2D, table 3 ).

In the HIV-infected group, high BP was most common among those who were overweight/obese as opposed to normal weight $(57.1 \%(\mathrm{n}=8 / 14)$ vs $24.5 \% \quad(\mathrm{n}=13 / 53)$; $\mathrm{p}=0.0193$ ). Whereas, in the HIV-uninfected group, clients who were underweight had normal $\mathrm{BP}$ relative to high BP $(24.3 \% \quad(n=43 / 177)$ vs $10.7 \% \quad(n=8 / 75)$; $\mathrm{p}=0.0138)$. In addition, a high proportion of males who were overweight/obese had high BP compared with normal BP $(34.7 \%(\mathrm{n}=17 / 49)$ vs $15.7 \%(13 / 83) ; \mathrm{p}=0.0117)$ (table 3$)$.

\section{DISCUSSION}

This study has shown that there is a high prevalence of HIV, NCD precursors and HIV-NCD precursor comorbidity among an urban, adult population in Johannesburg, South Africa; and could depict similar health burden outcomes within analogous geographical locations in South Africa. Men have significantly higher BP than women, even though females are significantly more overweight/obese than males. Women have significantly more HIV-infection than men, and there is an association between high BMI and hypertension among HIV-infected women. Overall, HIV-uninfected persons have higher BP compared with their HIV-infected counterparts among all age groups, and HIV-uninfected males have higher BP compared with HIV-infected males.Our study reports a higher HIV prevalence than the national prevalence. ${ }^{1}$ Over one-third of clients were overweight/obese, representing a higher prevalence of this BMI among black Africans as compared with the SADHS. ${ }^{11}$ The prevalence of high BP among our study participants is nearly three times that of a recent national general household survey conducted by Statistics South Africa, which reported an overall $10.4 \%$ prevalence of hypertension, as diagnosed by a medical professional. ${ }^{27}$

Our study results are compatible with national data regarding females having significantly more HIVinfections as compared with men ${ }^{28} 29$; a high prevalence of overweight/obesity among all age-groups which increased with age ${ }^{11}$; significantly more overweight/obesity among women $^{11}{ }^{30}$; and prevalence of hypertension increasing with age. ${ }^{31}$ However, our study's overall HIV prevalence was slightly higher than the national prevalence, ${ }^{5}$ with the majority of infections being clients $35+$ years of age. Onethird of all Zazi clients being overweight/obese represented a lower prevalence than reported by the SADHS for the black African population (67.4\% of women and $27.4 \%$ of men). ${ }^{11}$ We found all age-groups to exhibit a high prevalence of elevated BP, even the youth; and men had significantly higher BP than women. This contradicts the Statistics South Africa national household survey in which prevalence of high BP increased with age in both sexes and was higher in women for all age groups. ${ }^{27}$ 


\section{$\frac{0}{\frac{0}{m}}$

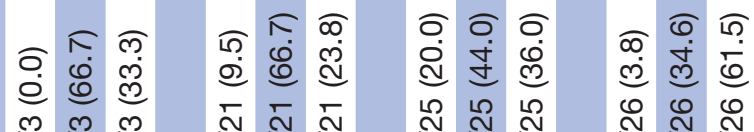

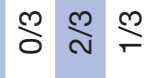

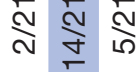

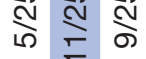

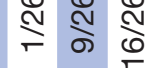 \\ ธุ \\ กิ \\ 家 \\ ए $\sqsubset$ \\ i $\stackrel{N}{N}$ \\ 을 峁 \\ $\frac{\frac{0}{m}}{\frac{0}{\pi}}$

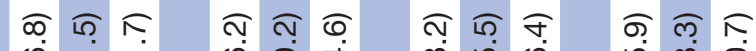 \\ @्ञ \\ o $ซ$ \\ लำ 守 \\ ठे के ठे \\ 过过

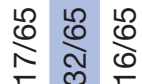 \\ 过㠻㠻 \\ Nิ \\ ले क्ले अे \\ 웜 웜 \\ in $\underset{N}{\stackrel{N}{N}}$ \\ ำก \\ ஸे \\ ఇ \\ के के ले}

ભ̆

웅

ब

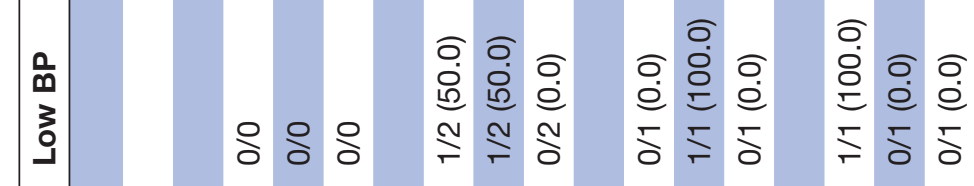

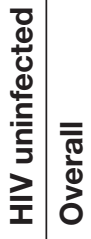

वิ สุ

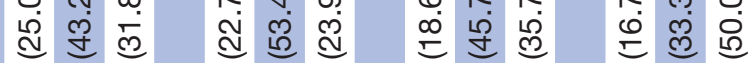

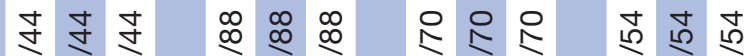

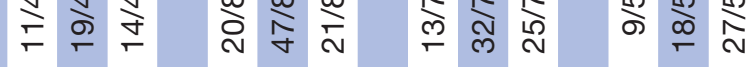

$\begin{array}{lll}0 & 0 \\ 0 & 0 & 0 \\ 0 & 0 & 0 \\ 0 & 0\end{array}$

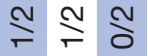

oิ

응

be

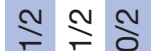

등

年

के

लं

สิ ช

음

ก N

¿

ले ले ले

뜸ำ

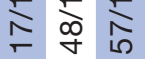

क्ले क्ठ

每

>

뜰

政

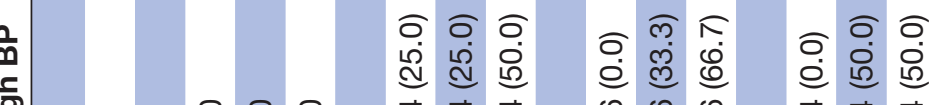

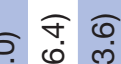

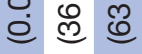

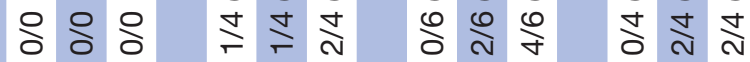

厂

ले ल

ก

ले

ल ल ल

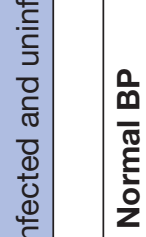

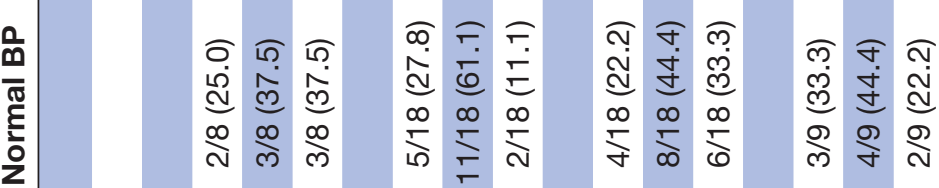

ণุ ซ ซ

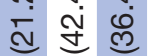

ल्ल ले ल्ल

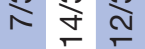

$r \frac{\pi}{r}$

$\frac{0}{\infty}$

ב⿱一土

웅

ฮิ

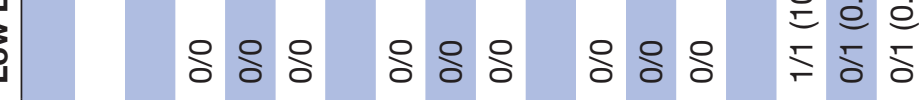

ㅇํㅇ ㅇํㅇ 용

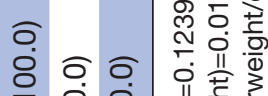

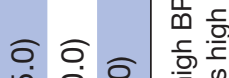

ம்

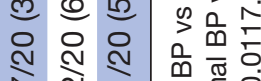

$\stackrel{i}{\stackrel{N}{N}}$

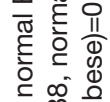

ㄴ.

응

Iㅡ능

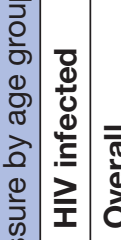

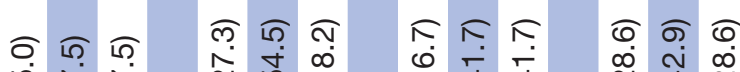

迎

สุ ลุ

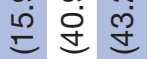

竎㠻辛

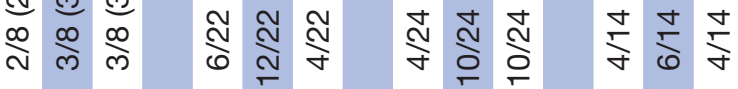

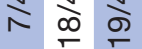

$\mp$ 당

要这

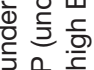

ธุ สิ สิ

ले

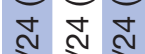

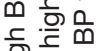

के ले

要

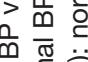

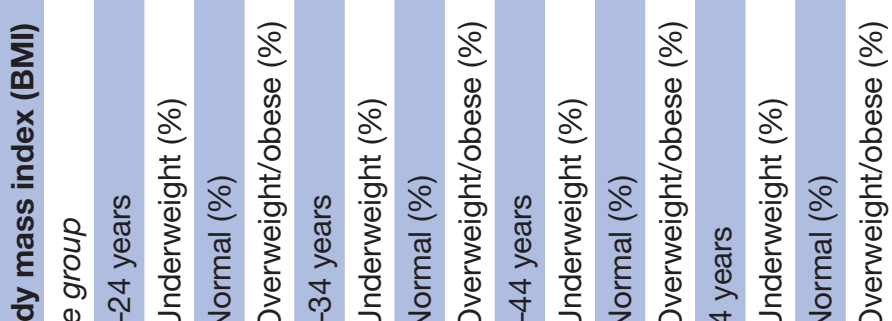

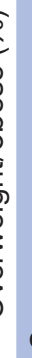

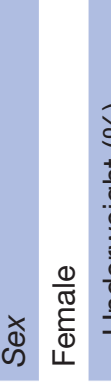

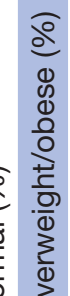

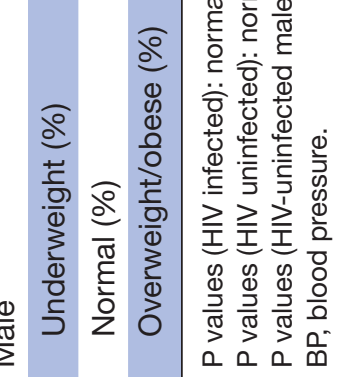


Additionally, it is possible that clinical practice guidelines used in South Africa are underdiagnosing elevated $\mathrm{BP}$ and hypertension, as they are more liberal than other scales utilised globally. While South Africa defines hypertension as $>140 / 90 \mathrm{~mm} \mathrm{Hg}$, the USA defines stage 1 hypertension being either systolic $130-139 \mathrm{~mm} \mathrm{Hg}$ or diastolic $80-89 \mathrm{~mm} \mathrm{Hg} .{ }^{32}$

When stratifying data by HIV-status, HIV-infected women have higher BP than HIV-infected men. The opposite is true for the HIV-uninfected group which is more reflective of the overall population. Previous studies suggest that hypertension in HIV-positive individuals is associated primarily with traditional risk factors such as being of older age, overweight and having other NCDs, such as diabetes and dyslipidaemia. ${ }^{33}$ Investigations have suggested a lower CD4 count as a strong independent predictor of hypertension in HIV-infected individuals through processes of persistent immune activation, chronic inflammation, endothelial dysfunction and microbial translocation associated with inadequate immune recovery. ${ }^{34-37}$ Of the 39 clients who had their CD4 count taken at Zazi, males had a lower median CD4 count than women (244 vs 365 cells $/ \mathrm{mm}^{3}$, respectively). While this does not support the hypothesis that lower CD4 count is linked with increased $\mathrm{BP}$ in HIV-infected individuals, it does follow the trend that men present to healthcare facilities later-and therefore often more sickly-than women. A systematic literature review yielded conflicting and inconclusive evidence to determine prevalence of hypertension in PLHIV and its association with ART and HIV-related and traditional risk factors-including sex. ${ }^{33}{ }^{38}$ Evidence has shown binge drinking and tobacco use increase the risk of NCDs. ${ }^{3940} \mathrm{~A}$ study using data from the WHO Study on global AGEing and adult Health Wave 1 showed smoking and hypertension were both risk factors of stroke among older South African adults. ${ }^{41}$ South Africa is ranked as having one of the highest consumption rates of absolute alcohol per drinker per year. ${ }^{42}$ In 2009, it was reported that $23.7 \%$ of South African adults smoked cigarettes, and while this is a $7 \%$ decrease since 1995 , the reduction has plateaued. ${ }^{43}$ Zazi men were more likely than women to consume alcohol and to smoke cigarettes which may account for their increased likelihood of elevated BP. ${ }^{44} 45$

Both longitudinal and cross-sectional study data have shown obesity to be a known independent risk factor for hypertension. ${ }^{46-48}$ This is shown within our study, as we found that elevated BP was associated with overweight/ obesity in women and not men. The majority of men with higher BP had a normal BMI. Studies have shown for every $1 \mathrm{~kg} / \mathrm{m}^{2}$ increase in BMI, there were between $1.3-1.7$ and $1.2-1.4 \mathrm{~mm} \mathrm{Hg}$ increases in BP for men and women, respectively. ${ }^{49}$ Furthermore, antihypertensive treatment mitigates the association of BMI with systolic BP by two-thirds. ${ }^{50}$ There is less data known on the relationship of body composition and BP in black African men. ${ }^{31}$

Our study demographics largely reflect that of the general population of Soweto-a nearly all black African, gender-balanced population of lower socioeconomic status, with the great majority speaking Zulu, followed by Sesotho. ${ }^{1451}$ The Zazi clinic, however, seems to draw more clients who have received higher education than that of the general population. ${ }^{52}$ Therefore, aside from having clients with an overall higher education, the Zazi study population does reflect the same demographics as the general population of Soweto and could be generalisable to similar geographical populations.

While the gender-balanced Zazi population is representative of the general population, there is conflicting literature to determine if it mimics typical attendance by sex within HTS centres. Literature historically shows men tend to be under-represented in HIV testing and treatment services in sub-Saharan Africa and globally. ${ }^{534}$ However, the latest SADHS reports that $69 \%$ of men had ever tested and $45 \%$ did so within the previous 12 months; not radically different from what our study has found. When stratifying our data by age-group and sex, only one age category (18-24 years) contained low male attendance (one-quarter) in comparison to their female counterparts. A study using data from three national HIV population-based household surveys (2005, 2008, 2012) reported sociodemographic factors linked to poor HIV testing uptake in men: being aged 15-24 years, of black African race group, being single and unemployed, and residing in urban informal and rural informal areas. ${ }^{54}$

Within the Zazi clinic, the two age-groups with the lowest attendance were 18-24 years and 45+ years, despite these age-groups comprising the two largest of the adult age demographics among the general population of Soweto (23.1\% and $20.3 \%$, respectively). ${ }^{55}$ Unfortunately, these are also the age groups largely related to the HIV transmission cycles in South Africa. HIV transmission dynamics in South Africa include cyclical intergenerational sex. ${ }^{56}$ Younger women (aged 15-24 years) tend to have agedisparate partners ( $5+$ years senior), with the odds of HIV infection increasing for each year increase in the male partner's age. ${ }^{57}$ Once older, these infected women have same-age relationships, infecting their male partners, who in turn infect younger women. ${ }^{58}{ }^{59}$ Furthermore, global data depict older women sharing many of the same risk factors for HIV as younger women, including lack of HIV prevention knowledge, having multiple sex partners (if divorced or widowed) and less likely to practice safer sex due to being postmenopausal and not of reproductive age. ${ }^{60}$ Unfortunately within South Africa, ageing women are not the target of HIV risk reduction programmes which focus on men and young women, ${ }^{61}$ and they are less likely to go for testing. ${ }^{60}$

Currently, South Africa and other low-income and middle-income countries (LMICs) largely provide government healthcare through vertical programmes of dedicated staff operating within separate physical spaces among facilities offering these services (ie, HIV, TB, NCDs). Large funders focus on specific diseases and are reluctant to fund costs for other conditions, which may increase the cost of service provision. ${ }^{62}$ Furthermore, 
combining HIV with other platforms, such as NCDs, has also been perceived as a threat to gains made in HIV control programmes. ${ }^{16}$ Disadvantages of vertical models are service duplication, inefficiency and service fragmentation. ${ }^{62}$

The WHO promotes integration as a solution. Intended outcomes are improved efficiency and quality of health services, and increased access and utilisation of health services between geographical and socioeconomic groups, leading to greater equity. ${ }^{62}$ Integrated care cascades require clinical space and skilled personnel, and it is necessary to leverage the existing infrastructure and build integrated care capacity of staff who have supported unilateral HIV programmes. ${ }^{16}$ While integration of HIV with other programmes, such as reproductive health and TB, has occurred through the establishment of inclusive national policies, evidence of HIV-NCD integration in clinical practice is scarce ${ }^{63-65}$ Five studies within LMICs which integrated an additional health service component into an existing service (eg, adding family planning or HTS to routine services) indicated that adding on services probably increases service utilisation and outputs of healthcare delivery. However, there is no evidence to date that a fuller form of integration improves healthcare delivery or health status. ${ }^{62}$

The top cause of death and disability worldwide are chronic NCDs, which attribute to more than three in five deaths ${ }^{66}$ with LMICs, such as South Africa, being disproportionately impacted. ${ }^{67}$ Successful ART programmes enable PLHIV to reach a near-normal life expectancy, ${ }^{20}$ and HIV infection is now considered a chronic condition requiring long-term management, just like NCDs. ${ }^{16}$ PLHIV are also at increased risk of NCDs,${ }^{21}$ and comorbidities of disease can be particularly devastating as they are compounded by the metabolic consequences of the roll out of ART medications. ${ }^{68}$ Our study population exhibited high rates of HIV, overweight/obese BMI and elevated BP across all age groups. HIV-infected females had higher BP than HIV-uninfected females, and HIVinfected people aged 18-24 and 35-44years were more overweight/obese than their HIV-uninfected counterparts. These precursors to NCDs increased the risk for HIV-NCDs comorbidities in these populations. Now, more than ever, healthcare must be integrated, and targeted interventions among these groups at HIV clinics could help reduce the risk of disease.

\section{Limitations}

Zazi only conducted STI symptoms screening and was unable to refer for asymptomatic STIs. One could assume the STI prevalence is higher in actuality. The clinic only screened for TB symptoms which is only the very beginning of the TB diagnostic algorithm and may not accurately describe the TB prevalence as other pathogens can cause TB symptoms. Without any other means of confirming $\mathrm{TB}$, it could be confirmed if the clients identified with TB symptoms actually had TB, needing to start treatment. The clinic did, however, have 34 clients who presented to Zazi with laboratory-confirmed TB (10.5\%). Unfortunately, the clinic was not able to collect CD4 count for all identified HIV-infected individuals; only for those who had not already initiated treatment and were not referred by the PHRU TB Clinic. Additionally, viral loads were not available, and therefore there were no ART referrals based on this biomarker. Responses to specific clinical questions were left to the interpretation and disclosure of the client. For example, questions surrounding drug use did not specify a timeframe (ie, within the last 6 months).

This study has a convenience sample of participants selfselecting to attend a single HTS clinic in Soweto. There is potential for bias as these participants have not been randomly sampled from multiple facilities. Some of our sub-group sample sizes for comparison are small which therefore affects statistical precision.

\section{CONCLUSION}

This study has shown a high prevalence of HIV-NCD comorbidity among an urban, adult population in Johannesburg, South Africa, which can be generalisable to similar settings. There is a need for an HIV-NCD integrated approach when considering health screening and interventions. A more holistic, patient-centred approach would benefit HIV-infected patients specifically, as NCD comorbidity can cause worsened conditions. Integrating screening for NCDs into HTS may increase service uptake. Targeted integrated interventions for HIV-infected females and HIV-infected people aged 18-24 and 35-44years could improve HIV public health outcomes. More studies on whether integrated healthcare screenings will improve the uptake of NCD treatment and improve health outcomes are required. There is also a critical need to revise the current national hypertension result category cut-offs in order to improve the prevention and treatment of this NCD precursor for both the general population and PLHIV.

\section{Author affiliations}

${ }^{1}$ Perinatal HIV Research Unit, Faculty of Health Sciences, University of the Witwatersrand, Soweto, South Africa

${ }^{2}$ School of Public Health, Faculty of Health Sciences, University of the Witwatersrand, Johannesburg, South Africa

${ }^{3}$ Health Systems Research Unit, South African Medical Research Council, Cape Town, South Africa

${ }^{4}$ Centers for Disease Control and Prevention, Pretoria, South Africa

${ }^{5}$ Office of the President, South African Medical Research Council, Cape Town, South Africa

Acknowledgements TD and GEG are funded by the South African Research Council and the National Research Foundation.

Contributors KLH conceptualised the study and manuscript and was the primary author. $\mathrm{KLH}, \mathrm{KH}, \mathrm{KO}$ and JD analysed and interpreted the data. MC and NK were technical advisors of the study and provided review of the manuscript. GG and TD provided conceptual contributions and review of the manuscript. All authors read and approved the final manuscript.

Funding The study was supported by the Cooperative Agreement to the Medical Research Council (MRC) ofSouth Africa for Tuberculosis Control and HIV Prevention, Care, and Treatment Activities under thePresident's Emergency Plan for AIDS 
Relief (PEPFAR) (Funding Opportunity Number: CDC-RFA-GH13-1340; Cooperative Agreement Number: 1U2GPS001150).

Disclaimer The findings and conclusions in this report are those of the authors and do not necessarily represent the official position of the funding agencies.

Competing interests None declared.

Patient consent for publication Not required.

Ethics approval The health programme was approved by the University of Witwatersrand, Human Research Ethics Committee. The approval number is 170 307.

Provenance and peer review Not commissioned; externally peer reviewed.

Data availability statement Data are available upon reasonable request.

Open access This is an open access article distributed in accordance with the Creative Commons Attribution Non Commercial (CC BY-NC 4.0) license, which permits others to distribute, remix, adapt, build upon this work non-commercially, and license their derivative works on different terms, provided the original work is properly cited, appropriate credit is given, any changes made indicated, and the use is non-commercial. See: http://creativecommons.org/licenses/by-nc/4.0/.

\section{REFERENCES}

1 Council, H.S.R. South African national HIV prevalence, incidence, behaviour and communication survey, 2017 (SABSSM), 2017.

2 W S, South Africa gears up to tackle cancer, non-communicable diseases. Cancer and tobacco control, non-communicable diseases (NCDS). The South African Health News Service, 2013.

3 Casper $\mathrm{C} \mathrm{CH}$, Menon M, et. al. HIV/AIDS Comorbidities: Impact on Cancer, Noncommunicable Diseases, and Reproductive Health., in Major Infectious Diseases. In: Holmes KK BS, Bloom BR, Jha P, et al, eds. Washington DC: The International Bank for Reconstruction and Development / The World Bank, 2017.

4 Health SANDo. National HIV testing services: policy and guidelines 2015, 2015.

5 Churchyard GJ, Mametja LD, Mvusi L, et al. Tuberculosis control in South Africa: successes, challenges and recommendations. S Afr Med J 2014;104:244-8.

6 Organization, W.H. Global tuberculosis report 2018. Geneva, 2018.

7 Johnson LF, Coetzee DJ, Dorrington RE. Sentinel surveillance of sexually transmitted infections in South Africa: a review. Sex Transm Infect 2005;81:287-93.

8 South African National AIDS Council. South Africa's national strategic plan for HIV, TB and STIs 2017-2022. Pretoria, 2017.

9 Organization., W.H. Global status report on noncommunicable diseases. Geneva, Switzerland, 2011.

10 TIMESLIVE. HIV infections on the rise in Gauteng - Research, 2018.

11 Survey SAHaD. Key indicator report, 2016.

12 GH P. Letters, words, worlds: the naming of Soweto. African Studies 1984;43:43-51.

13 Shisana O RT, Simbayi L, Parker W, et al. South African national HIV prevalence, incidence, behaviour and communication survey 2005. Cape Town, 2005.

14 Africa, s.s. Available: https://www.statssa.gov.za

15 Miller CL, Nkala B, Closson K, et al. The Botsha Bophelo adolescent health study: a profile of adolescents in Soweto, South Africa. South Afr J HIV Med 2017;18:a731.

16 Lane T, Raymond HF, Dladla S, et al. High HIV Prevalence Among Men Who have Sex with Men in Soweto, South Africa: Results from the Soweto Men's Study. AIDS Behav 2011;15:626-34.

17 Ruf V SS, Pretorius S, Kubheka S, et al. Medication adherence, selfcare behaviour and knowledge on heart failure in urban South Africa: the heart of Soweto study. Cardiovascular Journal of Africa 2010.

18 Organization, W.H. Consolidated guidelines on HIV counseling and testing (hCT. Geneva, 2015.

19 UNAIDS. 90-90-90, an ambitious treatment target to help end the AIDS epidemic, 2014.

20 Rutstein S. Steps to constructing the new DHS wealth index. Rockville, MD: ICF International, 2015.

21 Fry K FR, Chakraborty N. Measuring equity with nationally representative wealth Quintiles. Washington DC, 2014.

22 O'Rourke N PR, Hatcher L. A step-by-step approach to using SAS for factor analysis and structural equation modeling. SAS Institute, 2013.

23 Department of Health, M.R.C., Republic of South Africa. South Africa demographic and health survey 2003. Pretoria: Department of Health, Republic of South Africa, 2003.
24 Organisation, W.H. Body Mass Index - BMI, 2018. Available: http:// www.euro.who.int/en/health-topics/disease-prevention/nutrition/ahealthy-lifestyle/body-mass-index-bmi

25 Hypertension guidelines Working group: Seedat Yk, R.B., Veriava Y South African hypertension practice guideline 2014. Cardiovasc J Afr 2014;25:298-305.

26 Health, S.A.D.o. Tb control programme, 2018.

27 Hasumi T JK. Hypertension in South African adults: results of a nationwide survey. J Hypertens 2012;30:2098-104.

28 National Department of Health, R.o.S.A. 2015 national antenatal sentinel HIV and syphilis survey report. Pretoria, 2017.

29 Health, S.A.N.D.o. The fifth South African national HIV prevalence, incidence, behaviour and communication survey, 2017, 2017.

30 Shisana O LD, Rehle T, et al. The South African National health and nutrition examination survey, 2012: SANHANES-1: the health and nutritional status of the nation. Cape Town: HSRC Press, 2014.

31 Pisa PT, Micklesfield LK, Kagura J, et al. Different adiposity indices and their association with blood pressure and hypertension in middle-aged urban black South African men and women: findings from the AWI-GEN South African Soweto site. BMC Public Health 2018;18.

32 Whelton PK CR, Aronow WS, et al. 2017 ACC/AHA/AAPA/ABC/ ACPM/AGS/APhA/ASH/ASPC/NMA/PCNA guideline for the prevention, detection, evaluation, and management of high blood pressure in adults: a report of the American College of Cardiology/ American heart association Task force on clinical practice guidelines. J Am Coll Cardiol 2018;71:e127-248.

33 Hatleberg CI RL, d'Arminio Monforte A, Fontas E, et al. Data Collection on Adverse Events of Anti-HIV Drugs (D:A:D) Study Group., Association between exposure to antiretroviral drugs and the incidence of hypertension in HIV-positive persons: the Data Collection on Adverse Events of Anti-HIV Drugs (D:A:D) study. HIV Med 2018.

34 Ngatchou W LD, Ndobo P, et al. Increased burden and severity of metabolic syndrome and arterial stiffness in treatment-naive HIV+ patients from Cameroon," Vascular Health and Risk Management, vol. 9, no. 1, pp. 509-516, 2013. Vascular Health and Risk Management 2013;9:p. 509-516.

35 Ho JE HP. Cardiovascular manifestations of HIV infection. Heart 2009;96:1193-202

36 Stein JH, Hsue PY. Inflammation, immune activation, and CVD risk in individuals with HIV infection. JAMA 2012;308:405-6.

37 Manner IW, Baekken M, Kvale D, et al. Markers of microbial translocation predict hypertension in HIV-infected individuals. HIV Med 2013;14:354-61.

38 Balt CA. Hypertension and HIV infection. J Assoc Nurses AIDS Care 2013:24:S127-34.

39 Organization, W.H. Fact sheet: noncommunicable diseases. Geneva, 2018.

40 Soh AZ, Chee CBE, Wang Y-T, et al. Alcohol drinking and cigarette smoking in relation to risk of active tuberculosis: prospective cohort study. BMJ Open Respir Res 2017;4.

41 Ruan Y, Guo Y, Zheng Y, et al. Cardiovascular disease (CVD) and associated risk factors among older adults in six low-and middleincome countries: results from sage wave 1. BMC Public Health 2018;18:778.

42 Organization., W.H. Global status report on alcohol and health 2011. Geneva, 2011.

43 Bradshaw D SK, Levitt N, Nojilana B. Non-Communicable diseases a race against Time., MRC, editor. MRC Policy Briefs, 2011.

44 Madika AL M-VC. Smoking and blood pressure: a complex relationship. Presse Med 2017;46:697-702.

45 Messerli FH, Neagoe A, Messerli AW. The alcohol blood pressure paradox. Eur Heart J 2019;40:711-2.

46 Roger VL GA, Lloyd-Jones DM, Benjamin EJ, et al. Heart disease and stroke statistics-2012 update: a report from the American heart association. Circulation 2012;125:e2-220.

47 Wang Y, Wang QJ. The prevalence of prehypertension and hypertension among US adults according to the new joint National Committee guidelines. Arch Intern Med 2004;164:2126-34.

48 Wilson PW DAR, Sullivan L, Parise H, et al. Overweight and obesity as determinants of cardiovascular risk: the Framingham experience. Arch Intern Med 2002;162:1867-72.

49 Prospective Studies Collaboration. Body-mass index and causespecific mortality in 900000 adults: collaborative analyses of 57 prospective studies. The Lancet 2009;373:1083-96.

50 Chen Z SM, Du H, et al. China Kadoorie Biobank Collaborative Group, Blood pressure in relation to general and central adiposity among 500000 adult Chinese men and women. Int J Epidemiol 2015;44:1305-19.

51 KwaZulu-Natal Uo. The Soweto electricity crisis Committee, 2004. 
52 de Wet T PL, Korth M, Forrester C. Johannesburg poverty and Livelihoods study. Centre for Social Development in Africa: University of Johannesburg, 2008.

53 Shand T, Thomson-de Boor $\mathrm{H}$, van den Berg W, et al. The HIV blind spot: men and HIV testing, treatment and care in sub-Saharan Africa. IDS Bull 2014;45:53-60.

54 Makusha T, Mabaso M, Richter L, et al. Trends in HIV testing and associated factors among men in South Africa: evidence from 2005 , 2008 and 2012 national population-based household surveys. Public Health 2017;143:1-7.

55 M R. Demographic and urban characteristics of Soweto: a comparison of 1993 and 2008 in biennial conference of the economic Society of South Africa. Stellenbosch, 2011.

56 Akullian A, Bershteyn A, Klein D, et al. Sexual partnership age pairings and risk of HIV acquisition in rural South Africa. AIDS 2017;31:1755-64.

57 Evans M, Risher K, Zungu N, et al. Age-disparate sex and HIV risk for young women from 2002 to 2012 in South Africa. J Int AIDS Soc 2016;19:21310.

58 Maughan-Brown B, Kenyon C, Lurie MN. Partner age differences and concurrency in South Africa: implications for HIV-infection risk among young women. AIDS Behav 2014;18:2469-76.

59 Hopkins KL, Doherty T, Gray GE. Will the current national strategic plan enable South Africa to end AIDS, tuberculosis and sexually transmitted infections by 2022 ? South Afr J HIV Med 2018;19:a796.

60 Prevention, C.f.D.C.a. Hiv among people aged 50 and over, 2018. Available: https://www.cdc.gov/hiv/group/age/olderamericans/index. html
61 Durvasula R. Hiv/Aids in older women: unique challenges, unmet needs. Behav Med 2014;40:85-98.

62 Dudley L, Garner P, Cochrane Effective Practice and Organisation of Care Group. Strategies for integrating primary health services in low- and middle-income countries at the point of delivery. Cochrane Database Syst Rev 2011;4.

63 Matanje Mwagomba BLet al. Opportunities and challenges for evidence-informed HIV-noncommunicable disease integrated care policies and programs: lessons from Malawi, South Africa, Swaziland and Kenya. AIDS 2018;32:S21-32.

$64 \mathrm{C}$ vD. Integration of non-communicable chronic diseases (NCDS) and HIV/AIDS and mental health care through the involvement of chronically ill patients using empowerment evaluation. South African Family Practice 2015;57:337-46.

65 Haregu TN, Setswe G, Elliott J, et al. Integration of HIV/AIDS and noncommunicable diseases in developing countries: rationale, policies and models. Int J Healthc 2015;1:21-7.

66 Council, S.A.M.R. A silent killer: Why South Africa's health could crumble under pressure from non-communicable diseases. Cape Town, 2018.

67 Arokiasamy P, Uttamacharya K, Kowal P, et al. Chronic noncommunicable diseases in 6 low- and middle-income countries: findings from wave 1 of the world Health organization's study on global ageing and adult health (SAGE). Am J Epidemiol 2017;185:414-28.

68 Ghislain M, Bastard J-P, Meyer L, et al. Late antiretroviral therapy (art) initiation is associated with long-term persistence of systemic inflammation and metabolic abnormalities. PLoS One 2015;10:30144317. 